\title{
DIAGNOSIS IN NEW TECHNOLOGICAL LINE FOR STEEL FIBER PRODUCTION FOR PROCESS SAFETY
}

doi: $\quad 10.2478 /$ czoto-2019-0106

Date of submission of the article to the Editor: $30 / 11 / 2018$

Date of acceptance of the article by the Editor: 05/02/2019

Mikhail V. Doudkin ${ }^{1}$

Adam Idzikowski ${ }^{2}$ - orcid id: 0000-0003-1178-8721

Alina I. Kim ${ }^{1}$

Franciszek W. Przystupa ${ }^{3}$ - orcid id:0000-0002-6849-7151

Joanna Cyganiuk ${ }^{4}$ - orcid id: 0000-0002-7279-0692

${ }^{1}$ East-Kazakhstan State Technical University Kazakhstan

${ }^{2}$ Czestochowa University of Technology Poland, adam.idzikowski@wz.pcz.pl

${ }^{3}$ Wroclaw University of Technology Poland

${ }^{4}$ University of Zielona Gora, Poland

Abstract: Theoretical and experimental studies of new technology and equipment on the fulfilled cables and ropes of handling equipment are provided for diagnosis of main process. The result of the safe processing is steel fiber which is used further for production of a steel-fiber reinforced concrete. The research offered a number of essentially new diagnose methods which considerably increases engineering procedures of fiber production from waste.

Key words: Diagnosis, Technogenic waste, Fiber, Concrete, Energy efficiency

\section{INTRODUCTION}

The evidenced here of new technology and equipment on the fulfilled cables and ropes of handling equipment force us to create the conventional treatment of the diagnosing process. The presented considerations can only be a basis and starting point for a concretization of the design of diagnosing tools in a known technical situation. The presented examples concerning a new technology can be adapted to other processes. The most interesting problem that is not analyzed here concerns the logic of causes and places of damages and failures. Technical methods of diagnosing can be limited to economically acceptable methods (Przystupa, 2001, Idzikowski et al. 2017)

Nowadays mining and others, for example, construction entities, are forced to utilize this waste independently: their burial or warehousing is generally made. Of course, in this case, it is impossible to speak about effective conversion of this type of industrial wastes. At the same time this material (cables and ropes) are usually made of highquality steel with addition alloying elements that distinguishes these raw materials from regular industrial wastes. For the solution of this problem, the new technology 
and equipment for processing waste cables and ropes of handling equipment in steel fiber which is used further in production of steel-fiber reinforced concrete (SFRC) is offered.

\section{MODELLING AND EXPERIMENTAL RESEARCH}

In general, the technological line for the production of new fiber performs the following main processes: cutting cables (ropes) into segments of $50 \ldots 75 \mathrm{~mm}$, separating the steel cables (pieces) into individual wires, washing the resulting roughing fiber and then drying. This sequence of operations is well known (Rabinovich, 2011, Chernavin et al., 2013, Ashimov, 2013). For all these processes, based on scientific methods (experiment, analysis, modeling, etc.), new solutions have been developed and protected by patents, which make it possible to significantly reduce the cost of production.

Based on local economic considerations, it is proposed to use ropes and cables with a wire diameter from $0,2 \mathrm{~mm}$ to $1,0 \mathrm{~mm}$ that have developed the technical resource for manufacturing a new type of fiber. Practically all experiments carried out in this work (and considered below) used a rope with a diameter of 19.5 and $25 \mathrm{~mm}$, a cargo purpose, uncoated wire, unraveling, not straightened, normal accuracy.

Cutting of cables is the first and rather power-intensive production process of a fiber. Besides, solving a problem of matching of the most rational method of cutting, it is necessary to consider costs for consumable materials (replaceable disks, knives, etc.). It should be noted that now for cutting of cables and ropes abrasive circular saws are generally used. However, it concerns process of measuring cables cutting (on rather big pieces - from $1 \mathrm{~m}$ and above), and in our case it is high-speed cutting of cables on short pieces (50 ... $75 \mathrm{~mm}$ ).

Some cutting methods are not suitable for the new fiber production for technological reasons. Thus, using gas cutting, the metal is melted in the place of the cut, in connection with this, the strands are welded together, which makes it impossible to further process. The same effect occurs using plasma cutting. The cutting method using circular gear saws is also not suitable for this technology - when cutting a rope (free or clamped), the lower teeth of the rope engage the saw with a tooth, resulting in the effect of "pulling wires" (Fig. 1A). Cutting the guillotine cut is also not suitable for this technology, as it has a limited thickness of the metal being cut - in practice up to $6 \ldots 8 \mathrm{~mm}$. With a further increase in the thickness of the cut, the use of this method becomes economically unprofitable. Such process should be monitoted.

Diagnosing a process executed by a technical system or diagnosing the resulting state of the realizing object or a feature-based object in a process - is destined to reveal the real state or situation with regard to purposes and to the model. And finally - in identifying the damages and errors as well as in further aiding to diminish the level of their consequences, if it is impossible to prevent damages.

Acting without information or, what is worse, with unconscious use of faulty information - result in diminishing the effort of the system. Each system is changing generally being subject to inevitable degradation. According to assumptions, the system can be treated only during short periods of time as to be stabilized.

When monitoring some cutting methods (thermo-friction and abrasive circular saw), there are several technologically positive effects:

1) the effect of "falling apart" strands (Fig. 1C), which uniquely simplifies the further processing of cables / ropes (separation into individual wires); 
2) the effect of "releasing lubricant" - when cutting through heating, the lube is melted (with consequent leakage) of organic lubricant from ropes / cables, which on the one hand is a positive factor - the process of subsequent washing of fiber is facilitated; on the other hand, the problem of collecting and removal of waste data from the cutting zone (which complicates the overall design of the cable cutting machine). This effect also occurs when using laser cutting.

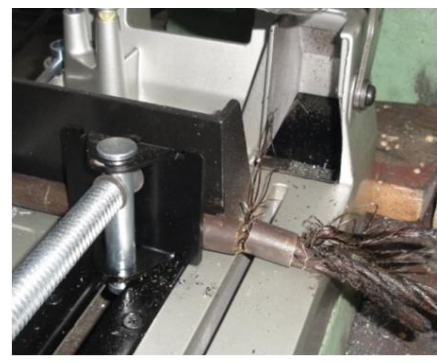

A

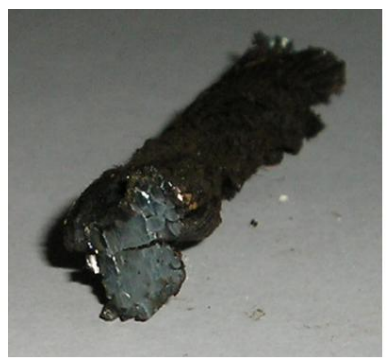

B

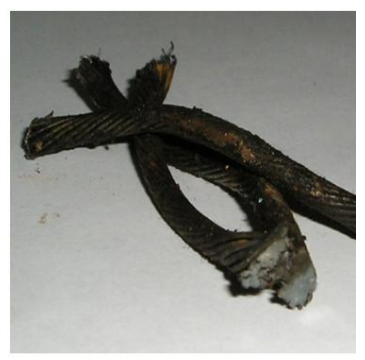

C

A - the effect of "pulling wires"; B - welding of wires; C - the "falling apart" effect

Fig. 1. Effects arising when cutting ropes / ropes

To solve the problem of the most rational method of cutting cables, a number of experiments and calculations were carried out to identify the most economical method. The results are shown on the graph (Fig. 2). Here, in calculating the cost of cutting one ton of cables, energy consumption and the cost of consumables were taken into account. In all cases, the cutting time was taken into account, in order to ensure a certain productivity of the entire production line - at least 2 tons of fiber per shift. This productivity is derived from local economic considerations. The remaining cutting parameters are not taken into account, as having insignificant influence.

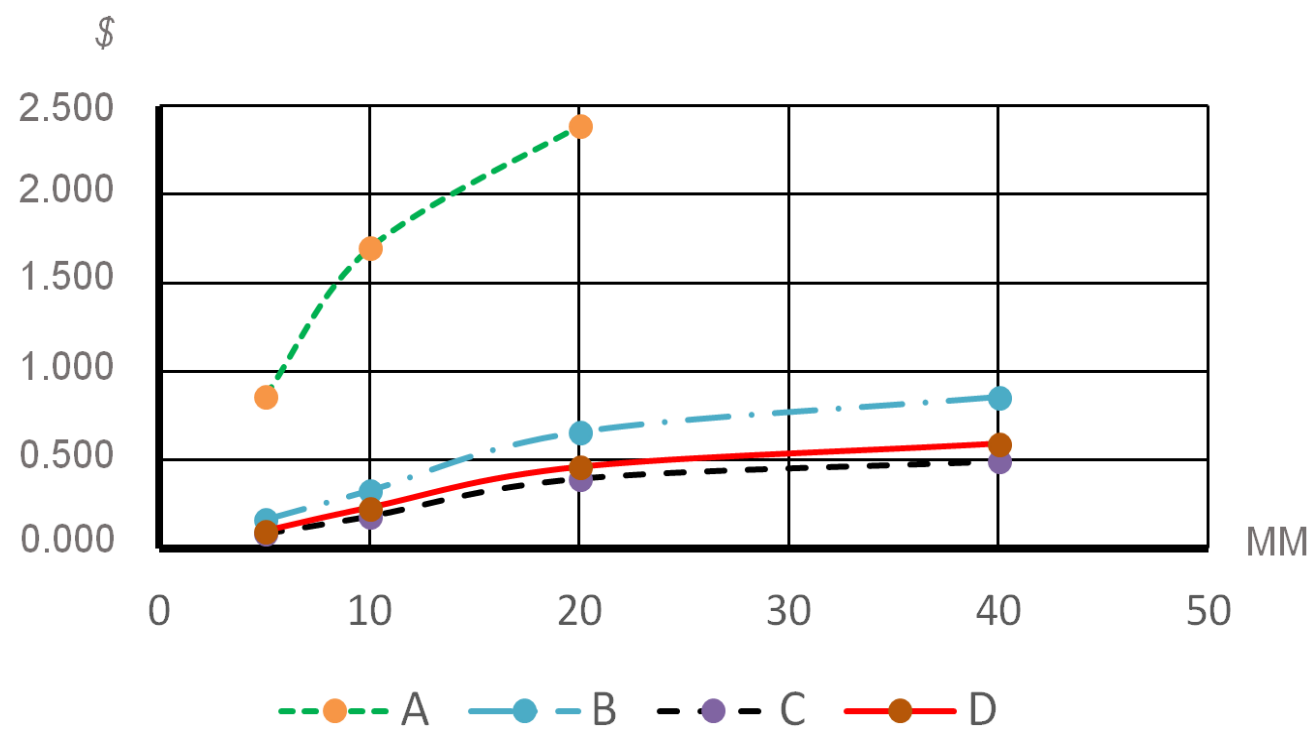

Fig. 2. The specific generalized cost of cutting (US dollars) of cables/ropes in various ways

Apparently from the submitted data, it is not appropriate to apply ways of hydroabrasive and laser cutting in our case. And laser cutting cannot be applied and for the technological reasons - is unsuitable with a diameter of cable over $20 \mathrm{~mm}$. 
Based on the obtained conclusions, the original experimental-pilot installations (Fig. 7) of thermofriction and abrasive cutting of cables were designed and manufactured. In the course of experiments, a new original design of the disc for thermofriction cutting of cables was proposed, protected by the patent (Ashimov, 2013).

The second important technological process in the production of fiber is separation of cut pieces of ropes / cables into separate strands and then into individual wires (hereinafter - "cable separation"). As research has shown, this process has the greatest energy intensity in the whole technological chain.

The authors for the first time proposed a fundamentally new solution to this problem, which makes it possible to reduce the energy intensity of the separation operation several times. The solution is use a single level crusher. In this case, only one roll is used, and the pressure is created by the crushing plate, which is subjected to additional vibrating action. A patent (Doudkin et al., 2016) was received for this decision.

To implement and test the proposed method of cable separation, experimental and then industrial installations were developed and manufactured (Fig. 7). In this case, it became necessary to determine the following main parameters of the unit: amplitude and frequency of oscillations; acceleration of moving elements of the structure; drive power and others. The basic scheme of the installation for cables separation is shown in Figure 3.

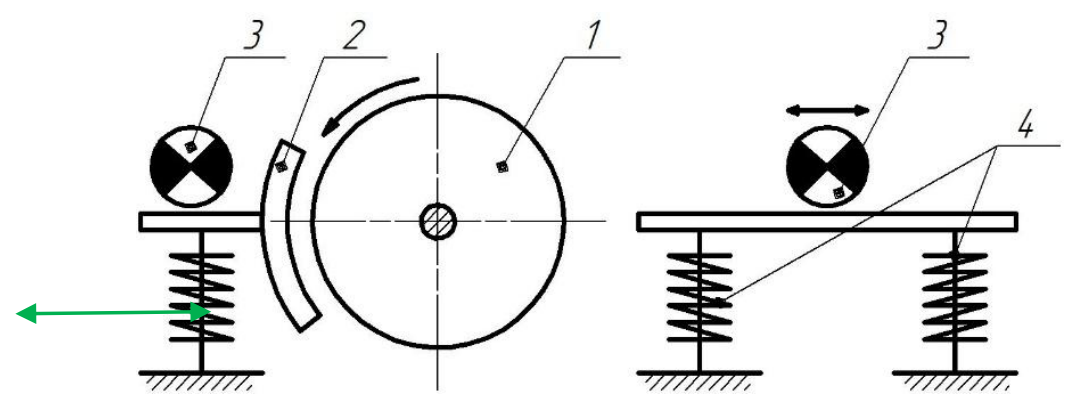

1 - roll; 2 - crushing plate, 3 - vibrating drive; 4 - vibration mounts.

Fig. 3. Schematic installation diagram for the separation of cables

The rational dimensions and operating modes of this installation were originally calculated using computer models (Figure 4).
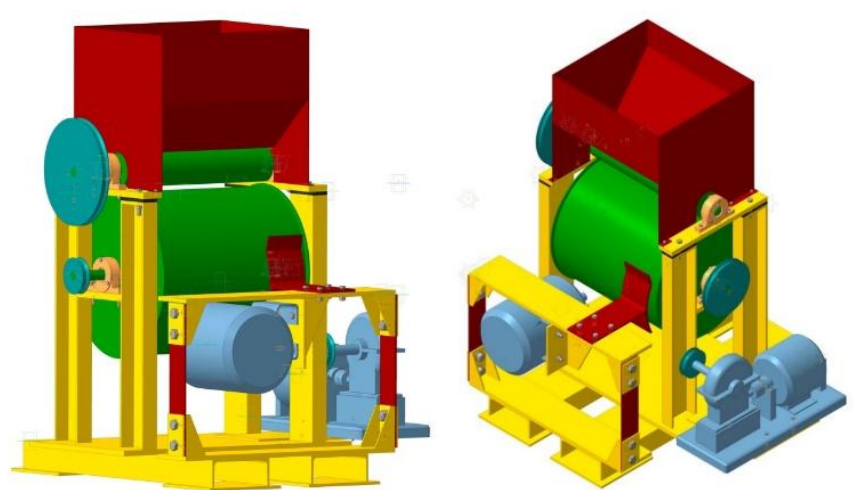

Fig. $4-3 D$ model of the installation for cables separation

On the experimental set-up (after computer simulation) of the unit for cable separation, a number of experiments were carried out, which fully confirmed its 
effectiveness. In the course of the experiments, the main task was to establish such an operating mode of the installation (amplitude and frequency of oscillations of the moving plate, and speed of the main drum), which ensures complete separation of the cut pieces of wire for individual wires for a minimum time. Efficiency of separation- E\% was estimated as a percentage of the total wires number in the cable to the number of free (after separation) wires.

Some of the obtained results in course of experiments are shown in Fig. 5. From the presented graph it can be seen that the most rational operating mode of the unit corresponds to the minimum vibration frequencies of the plate (rpm - the vibration speed of the vibration drives) and main drum - about 997 and 36 rpm (respectively). At the same time, the experiment showed that further reduction leads to decrease in productivity, that is, not rationally (not shown in the graph). The most acceptable are the average values of oscillation amplitude of the vibroplate - about $0.6 \ldots 1 \mathrm{~mm}$. At the same time, the same behavior of graphs confirms the adequacy of the obtained data (Idzikowski et al., 2017).

The next important technological process in the fiber production is obtained wire washing during the cables separation - a roughing fiber. Wash the cables is an obligatory process, because otherwise the organic lubrication of cables and other impurities do not allow to obtain the required quality parameters of steel-fiber reinforced concrete. This process can also have significant energy intensity (especially when using heated water), in addition, the use of standard detergent solutions significantly increases the cost of the operation (Idzikowski et al., 2017).

During the analysis of various sources, it was revealed that for today there are no aggregates of roughing fiber that are optimally suitable for effective use. We proposed our own new design of the vibrating washing and the corresponding new way of washing, which are protected by the innovative patents (Doudkin et al., 2016)

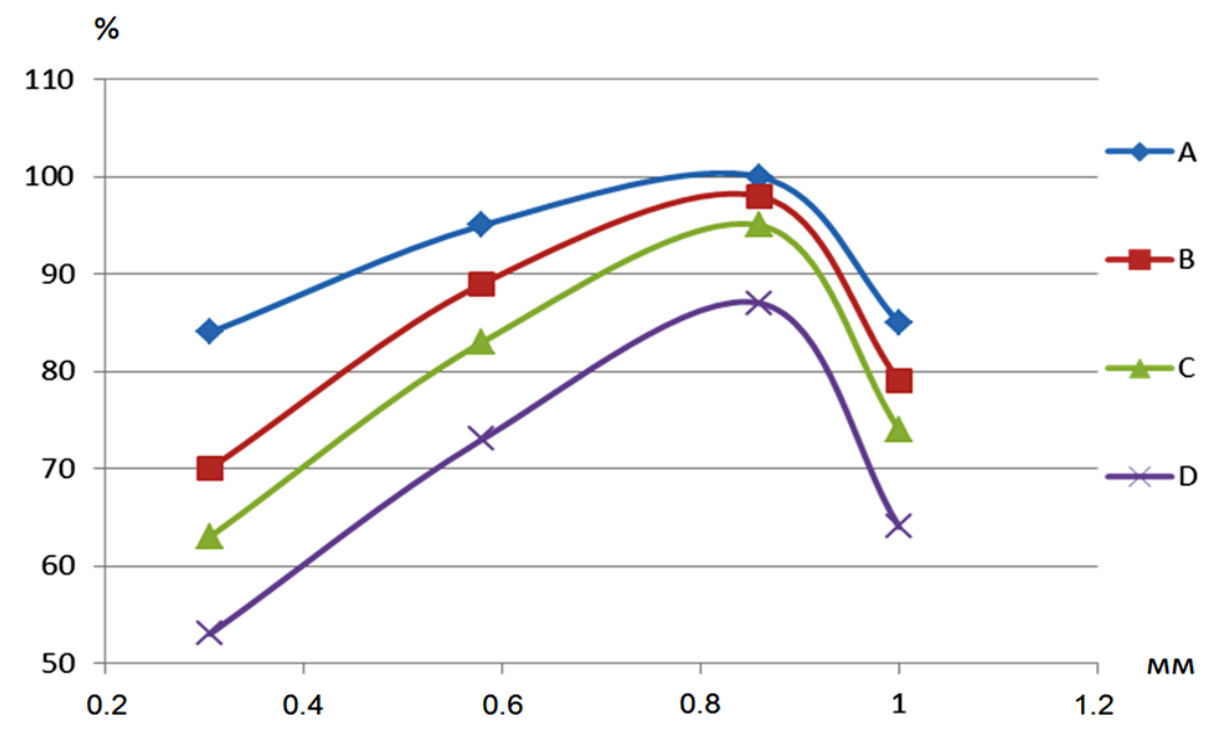

Line A: $\mathbf{n}=997 \mathrm{rpm}, \mathrm{N}=36 \mathrm{rpm}$; Line $\mathrm{B}: \mathbf{n}=1491 \mathrm{rpm}, \mathrm{N}=36 \mathrm{rpm}$;

Line $C: \mathbf{n}=997 \mathrm{rpm}, \mathrm{N}=72 \mathrm{rpm}$; Line $\mathrm{D}: \mathbf{n}=1491 \mathrm{rpm}, \mathrm{N}=72 \mathrm{rpm}$.

Fig. 5. Dependence of separation efficiency (E, \%) on the amplitude of the plate $(A, \mathrm{~mm})$ and the vibration frequency of the plate $(n, r p m)$, and the main drum speed $(N, r p m)$ 
In addition, effective washing solution has been developed (together with chemists). All components of the solution have low cost and low environmental hazard. The detergent solution is also protected by the patent (Doudkin et al., 2016). Its main advantage is able to clean the roughing fiber without heating the water.

The all solutions effectiveness for roughing fiber washing has been proved experimentally. At the same time, the cost of the washing operation compared to taxes is reduced by 2 ... 2.5 times (Idzikowski et al., 2017).

Thus, considering the above, it can be concluded that it has been proposed in general a new technological line for the production of fiber from man-made waste. The prototypes of the main equipment of this line are presented in Figure 6. The main feature of all solutions is significant reduction in production costs, mainly due to energy efficiency.

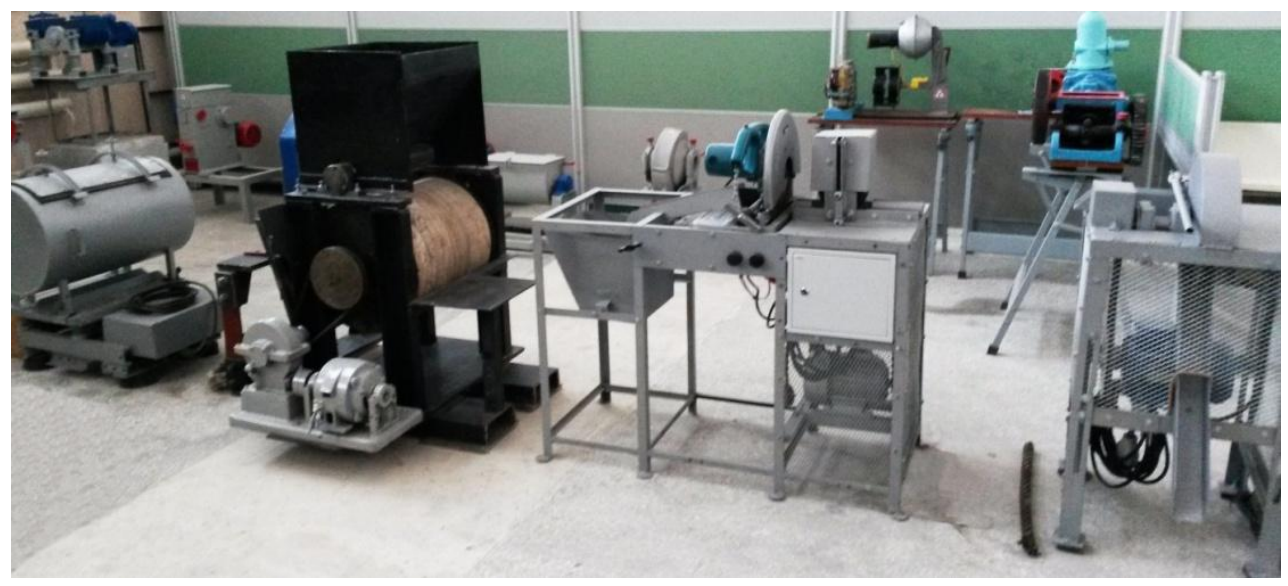

Fig. 6. Experimental samples of the main equipment (in the foreground) of the new production line (from left to right: vibro wash, device for cables separation, semi-automatic for abrasive cables cutting, unit for thermofriction cutting)

Experimental studies of the new fiber and SFRC on its basis were conducted in accordance with requirements of international norms and standards. Some samples obtained during the experiments are shown in Figures 7 and 8 . The findings are obtained in the following section (Doudkin et al., 2016, Doudkin et al., 2013, Doudkin et al., 2013, Kim et al., 2017).

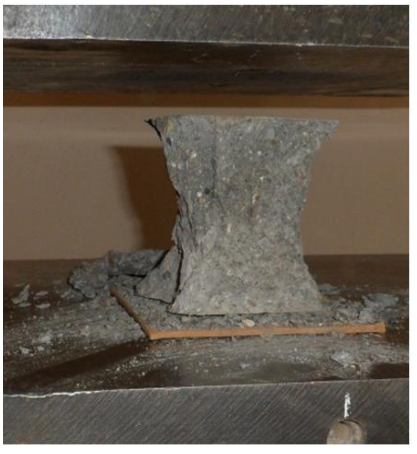

a

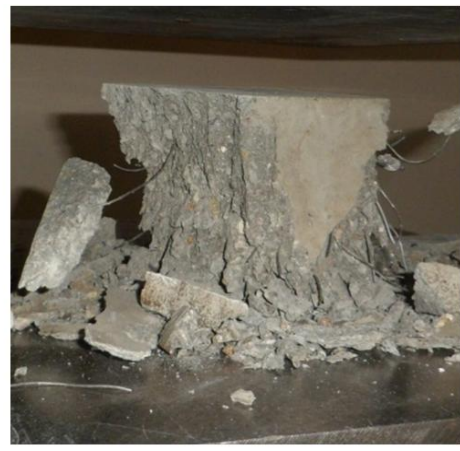

b

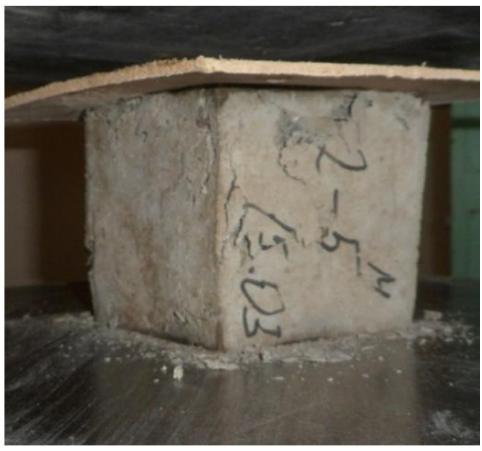

$\mathrm{C}$

$a-$ concrete matrix; $b-1 \%$ of reinforcing, $c-2 \%$ of reinforcing

Fig. 7. Samples of cubes after compression test 


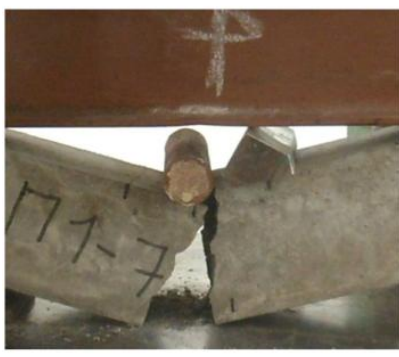

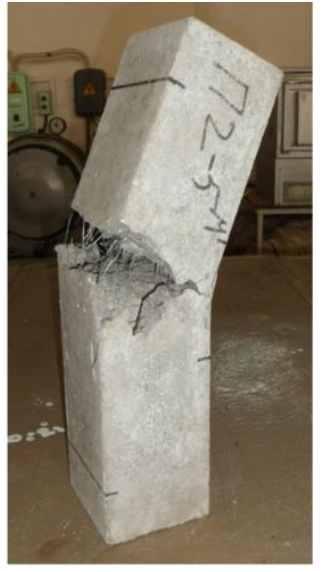

b

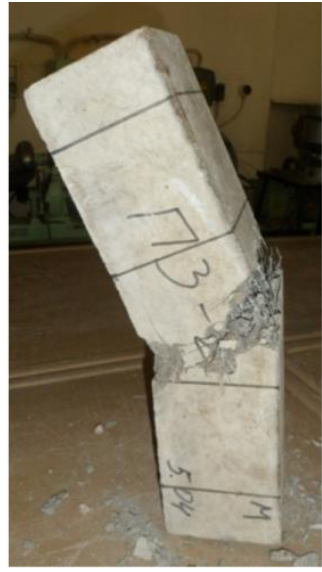

C

$a-$ concrete matrix; $b-1 \%$ of reinforcing, $c-2 \%$ of reinforcing

Fig. 8. Samples of steel-fiber-concrete prisms after the tensile test

\section{DIFFERENTIAL METHOD DIAGNOSIS OF PROCESS}

The differential method is a typical example of a system-based application of the generalized method of state evaluation. This method, well known in medicine, is transferred into other domains. The most advantageous feature of the method is the possibility of diagnosing without knowledge about the object of observation.

In a of the new production line special tools can be proposed to compare images, learning with an incorporation of dedicated media, as magnets, gravimeters, etc. For cables separation, conditions of application of the method exist, namely:

- there exists a potential of creation of standards, their interchange and replacement, rejection, redundancy for uncertain situations, confirmation of inferring logics, overloads, changes of trends and their creation, degradation characteristics, failures and catastrophes.

- for machinery by use of well-known observation techniques (identity of processes),

- for general technical systems with similar space structure (linear characteristics of object distribution), by application of methods of signal acquisition,

\section{CONCLUSIONS}

The carried out complex of theoretical and experimental studies of new technology and equipment for the waste processing allowed proposing new solutions in this field. The received data allow speaking about the further commercial prospectivity of introduction of the offered decisions. In the process of further project implementation, it is expected that the proposed technology and equipment will be finalized in pilot industrial conditions.

In the new production line special diagnose tools can be proposed to compare images, learning with an incorporation of dedicated media, as magnets, gravimeters, etc. For cables separation, conditions of application of the method exist.

The presented results served as the basis for the creation of an innovative production enterprise diagnosis for the fiber production from technogenic waste. 


\section{REFERENCES}

Ashimov, B.A. 2013. The Strength and deformability of steel fiber concrete and slab constructions with the use of fiber from used steel ropes. The Dissertation on competition of a scientific degree of candidate of technical Sciences, Moscow, 147.

Chernavin, V., Seraya, N., Zatonov, G., Bedenko, Y. 2013. Perspectives of steel fiber concrete application with using of dispersed reinforcing from used ropes. Modern Challenges and Decisions of Globalization. International Conference. July 15, 2013. New York, USA. P.2, S.: Kazakhstan,USA, Bozeman, 63-66.

Doudkin, M.V., Guryanov, G.A., Vavilov, A.V., Hon, N.V., Klimenko, E.A., Likunov, A.V. 2016. Adevice for vibrating the cleaning products. The patent for useful model No. 1401. IPC B08B 3/10. Published 15.03.16, Bulletin \# 4.

Doudkin, M.V., Guryanov, G.A., Vavilov, A.V., Khon, N.V. 2016. Device for splitting a steel cable on a separate wire. Innovative patent of RK No. 31038. IPC B23D 31/02. Published 15.04.2016, Bulletin \# 4.

Doudkin, M.V., Guryanov, G.A., Vavilov, A.V., Khon, N.V., Kasym, D.S. 2016. Disc knife for cutting ropes. The patent for useful model № 1403. B23D 35/00 IPC. Published 15.03.16, Bulletin \# 3.

Doudkin, M.V., Guryanov, G.A., Vavilov, A.V., Khon, N.V., Klimenko, E.A., Likunov, A.V. 2016. Method of washing parts. Innovative patent of RK No. 31037. IPC B08B 3/10. Published 15.04.2016, Bulletin \# 4.

Doudkin, M.V., Guryanov, G.A., Vavilov, A.V., Seraya, N.V. 2016. Cleaning solution for cleaning rough fibers. Innovative patent of RK No. 31155. IPC C11D 1/00. Published 16.05.2016, Bulletin\#5.

Doudkin, M.V., Pichugin, S, Fadeev, S., 2013. Contact Force Calculation of the Machine Operational Point. Life Science Journal, 10 (39) (2013), 246-250.

Doudkin, M.V., Pichugin, S. , Fadeev, S., A. Vavilov, 2013. Calculation of the Interaction of Working Body of Road Machine with the Surface. Life Science Journal, 10 (133)(2013), 832-837.

Doudkin, M.V., Pichugin, S., Fadeev, S., 2013. Studying the Machines for Road Maintenance. Life Science Journal, 10 (24)(2013), 134-138.

Doudkin, M.V., Pichugin, S. Fadeev S., 2013. The Analysis of Road Machine Working Elements Parameters. World Applied Sciences Journal, 23 (2013), 151-158.

Idzikowski, A., Doudkin, M.V. Fröhilich, S.R. et al., 2017. Modelling of machinery processes. Monograph, vol. II, Publishing Office of Faculty of Menagement Czestochowa University of Technology, Czestochowa.

Idzikowski, A., Doudkin, M.V. Przystupa, F.W. et al., 2017. Modelling of machinery processes. Monograph, vol. I, Publishing Office of Faculty of Menagement Czestochowa University of Technology, Czestochowa.

Kim, A., Doudkin, M.V., Vavilov, A., Guriyanov, G., 2017. New vibroscreen with additional feed elements. Archives of Civil and Mechanical Engineering, 17 (4) (2017), 786-794. http://doi.org/10.1016/j.acme.2017.02.009

Przystupa, F.W., 2001. Diagnostics of a wide area object; case of systems of belt conveyors. SYSTEMS, Vol. 6/1-2, 2001, pp. 135-157, Oficyna Wydawnicza Politechniki Wrocławskiej, Wroclaw.

Rabinovich, F.N. 2011. Composites based on dispersion-reinforced concrete. Theory and design, technology, structures. Monograph, M.: Publishing house ASV - 642. 